\title{
An Improved Dynamic Modeling of Permanent Magnet Synchronous Machine with Torque Ripple Characteristics
}

\author{
S. A. Kim, J. H. Song, S. W. Han, and Y. H. Cho
}

\begin{abstract}
A mechanical vibration and acoustic noise of permanent magnet synchronous machines (PMSM) are caused by the torque ripple due to the non-sinusoidal back electromotive force (BEMF). The accurate modeling with a torque ripple is essential to improve the torque characteristics of PMSM. The torque ripple that appears because of the interaction between the flux of the PM and the stator teeth. A general dynamic modeling of PMSM has only a magnetic torque and a reluctance torque. Therefore, the dynamic modeling of the PMSM is a need to apply the influence of the harmonics. This paper proposes an improved modeling of the PMSM considering the torque ripple characteristics. The theoretical basis of the torque ripple and individual definition of the model block is explained. The effectiveness of this proposed modeling is verified by the simulation and experiment according to the comparison of the output characteristics between the traditional and proposed modeling.
\end{abstract}

Index Terms-Back electromotive force harmonics, fast fourier transform, permanent magnet synchronous machine, torque ripple, modeling.

\section{INTRODUCTION}

Permanent magnet synchronous machines (PMSM) are used in many industrial application and household appliances because they offer a highly efficient, high power-density, low size alternative to other machines such as induction machine (IM) and switched reluctance motor (SRM) [1]. However, PMSM has torque ripple which referring to a periodic increase or decrease in output torque as the motor shaft rotates. Torque ripple generates the mechanical vibration and the acoustic noise [2]-[4].

The general dynamic modeling of the PMSM is derived using a two phase machine because this approach has the conceptual simplicity with only one set of two windings on the stator [5]. The method is used for performance simulation and control system design [6]. However, the parameters of the PMSM, $d$ and q inductances, vary load condition and current phase angle. The variation of the parameters affects the output

Manuscript received May 23, 2017; revised August 1, 2017. This research was supported by railway technical research program through the Korean Agency for infrastructure Technology Advancement (15RTRP-B091404-02) and by Basic Science Research Program through the National Research Foundation of Korea grant funded by the Korea Government No: NRF- 2014R1A2A2A01003368.

S. A. Kim J. H. Song, and Y. H. Cho are now with Dong-A University, Busan, Korea (e-mail: y3k9s1@ nate.com, gluttonboy@nate.com, yhcho@dau.ac.kr).

S. W. Han is now with Busan Transportation Corporation, Busan, Korea (e-mail: h111641@ humetro.busan.kr). characteristics such as output torque and velocity [7]. For this reason, in order to improve the accuracy in the performance of dynamic modeling, the $\mathrm{d}$ and $\mathrm{q}$ inductances data calculated by finite element analysis (FEA) and Experiment is applied in the modeling of the PMSM. However, it cannot derive the torque ripple characteristics because of the interaction between the flux of the PM and the stator teeth. To overcome the drawbacks, an improved method is presented for computation of the back electromotive force (BEMF) harmonics using the fast fourier transform (FFT). This method allows the torque ripple to be calculated with the BEMF harmonic according to the machine speed.

Therefore, the improved modeling, based on the FFT result of the BEMF, is proposed for the PMSM. The performance of the PMSM with torque ripple characteristics is simulated with the use of the proposed modeling. This paper present the analysis method for the accurate modeling considering the non-sinusoidal BEMF and is verified by comparison with experimental result.

\section{COMPUTATION OF HARMONICS BY FEA}

\section{A. FEA Result}

The designed specification of the PMSM is listed in Table I, and the PMSM structure and a potential distribution using the FEA are illustrated in Fig. 1. Fig. 2 shows the phase BEMF and FFT result for the PMSM. The phase back EMF has 5th, 9th and 11th order harmonics. The 5th order harmonic component is dominant, the magnitude of this component is $8.2 \%$ of the fundamental component. The PMSM parameters are listed in Table II.

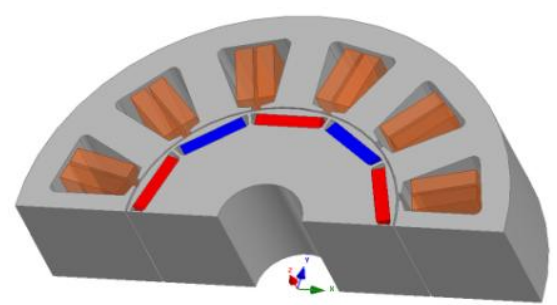

(a)

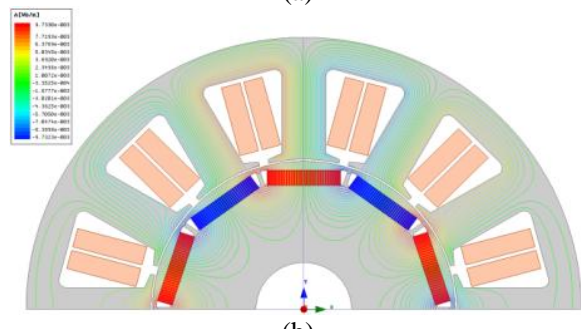

(b)

Fig. 1. PMSM structure and potential distribution using FEA: (a) Structure. (b) Potential distribution. 
TABLE I: THE SPECIFICATIONS OF PMSM

\begin{tabular}{ccc}
\hline \hline Item & Unit & Value \\
\hline Rated torque & $\mathrm{Nm}$ & 17.6 \\
Power & $\mathrm{W}$ & 1800 \\
Rated speed & $\mathrm{rpm}$ & 1000 \\
\hline \hline
\end{tabular}

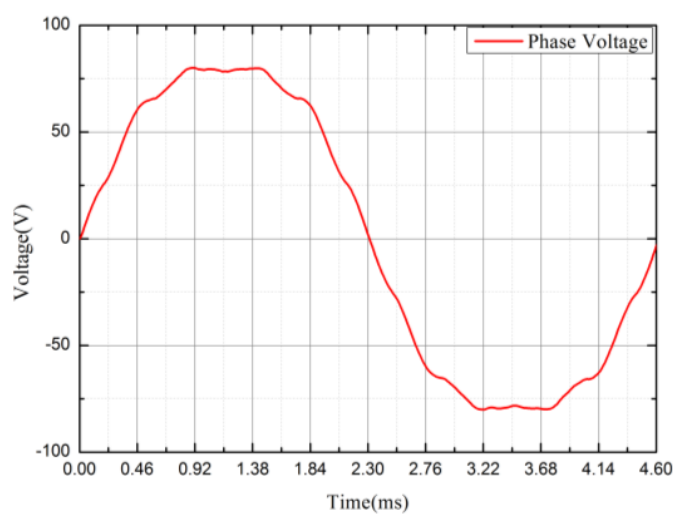

(a)

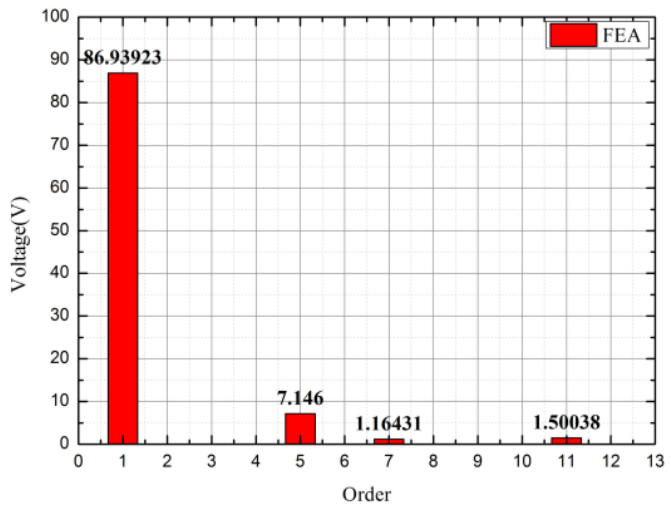

(b)

Fig. 2. FEA results: (a) BEMF at 1000rpm. (b) FFT result.

TABLE II: PMSM PARAMETERS

\begin{tabular}{ccc}
\hline \hline Item & Unit & Value \\
\hline Stator Resistance & $\Omega$ & 0.276 \\
$d$ axis inductance & $m H$ & 4.75 \\
$q$ axis inductance & $m H$ & 7.8 \\
BEMF constant & $V_{p k} / \mathrm{krpm}$ & 155.779 \\
Number of pole & - & 10 \\
Moment of Inertia & $\mathrm{Kg} \cdot \mathrm{m}^{2}$ & 0.0279 \\
\hline \hline
\end{tabular}

\section{B. Experimental Results}

Fig. 3 shows the stator and rotor of the PMSM. Fig. 4 shows the measured the BEMF at 1000rpm and FFT result. Compared with Fig. 2, the magnitude of the BEMF is lower than FEA result. However, the calculated harmonics from the machine are about similar than the FEA estimated one.

\section{ModELING OF PMSM}

\section{A. Conventional Modeling}

The three phase voltage equations for the PMSM can be written as follows:

$$
v_{a b c}=R_{s} i_{a b c}+\frac{d}{d t} \lambda_{a b c n}
$$

Based on the three phase voltage equations and transformation matrixes, the stator voltage equation is represented by the rotating reference frame [8]. The $d$ and $q$ axis flux linkage component are represented by:

$$
\lambda_{d s}^{r}=\lambda_{f}+L_{d} i_{d s}^{r}, \lambda_{q s}^{r}=L_{q} i_{q s}^{r}
$$

Fig. 5 shows the simplified equivalent circuit of the PMSM in the $d q$ reference frame. Where $R_{s}$ is the resistance of the stator per phase, $L_{d}$ and $L_{q}$ is the $\mathrm{d}$ and q inductance, and $e_{d}$ and $e_{q}$ is the $d$ and $q$ BEMF. From the analysis of the equivalent circuit, the $d q$ axis voltage equation of the PMSM can be given as [9]:

$$
\begin{gathered}
v_{d}=R_{s} i_{d s}^{r}+L_{d} \frac{d i_{d s}^{r}}{d t}-\omega_{e} L_{q} i_{q s}^{r} \\
v_{q}=R_{s} i_{q s}^{r}+L_{q} \frac{d i_{q s}^{r}}{d t}+\omega_{e} \lambda_{f}+\omega_{e} L_{d} i_{d s}^{r}
\end{gathered}
$$

The electromagnetic torque is the result of the sum of different components as follows:

$$
T_{e}=\frac{3}{2} \frac{P}{2} \lambda_{f} i_{q s}^{r}+\frac{3}{2} \frac{P}{2}\left(L_{d}-L_{q}\right) i_{d s}^{r} i_{q s}^{r}
$$

The first component is the magnetic torque and second component is the reluctance torque [10].

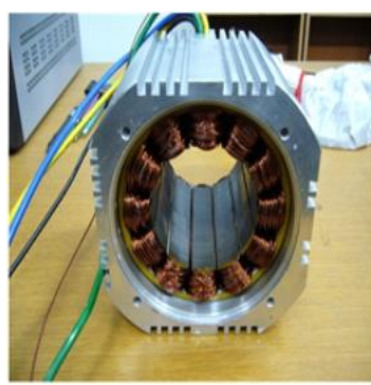

(a)

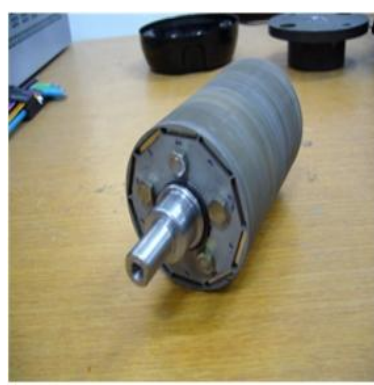

(b)
Fig. 3. Stator and rotor of PMSM: (a) Stator. (b) Rotor

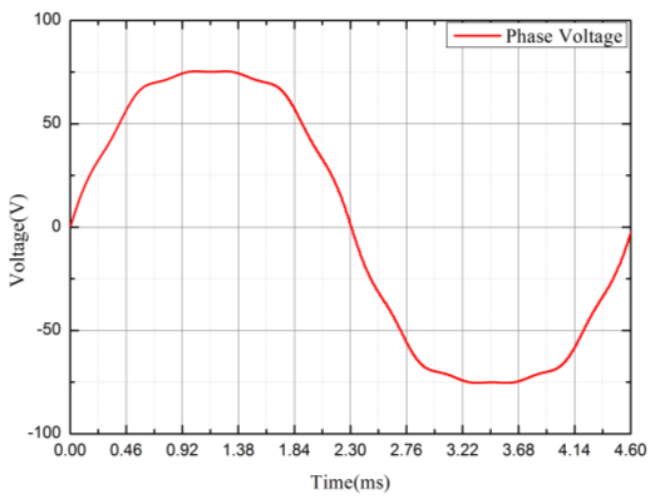

(a)

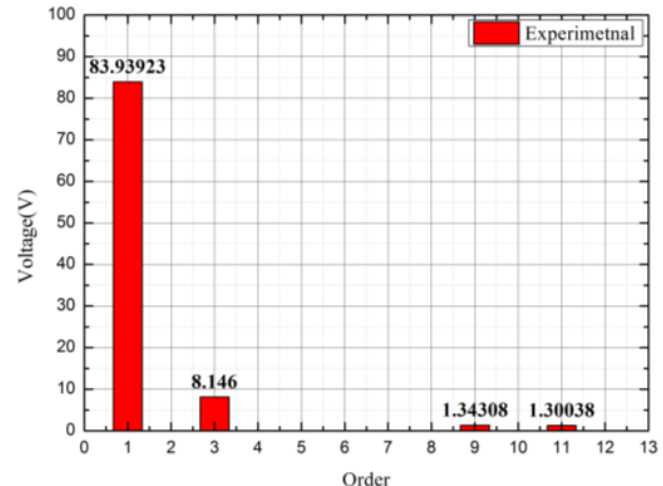

(b)

Fig. 4. Experimental results: (a) BEMF at 1000rpm. (b) FFT result 


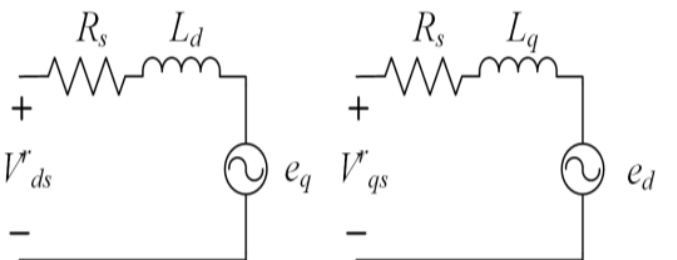

Fig. 5. Simplified equivalent circuit of the PMSM in the $d q$ reference frame.

\section{B. Proposed Modeling}

From (4), the electromagnetic torque has another component. The third component represents the ripple torque that appears because of the interaction between the flux of the PM and the stator teeth. From (1), the three phase flux linkages are represented by:

$$
\begin{aligned}
& \lambda_{a s}=\lambda_{f 1} \sin \left(\theta_{r}\right)+\lambda_{f 5} \sin \left(5 \theta_{r}\right)+\lambda_{f 7} \sin \left(7 \theta_{r}\right) \\
& +\lambda_{f 11} \sin \left(11 \theta_{r}\right)+\lambda_{f 13} \sin \left(13 \theta_{r}\right)+\ldots \\
& \lambda_{b s}=\lambda_{f 1} \sin \left(\theta_{r}-2 / 3 \pi\right)+\lambda_{f 5} \sin \left(5 \theta_{r}-2 / 3 \pi\right) \\
& +\lambda_{f 7} \sin \left(7 \theta_{r}-2 / 3 \pi\right)+\lambda_{f 11} \sin \left(11 \theta_{r}-2 / 3 \pi\right) \\
& +\lambda_{f 13} \sin \left(13 \theta_{r}-2 / 3 \pi\right)+\ldots \\
& \lambda_{c s}=\lambda_{f 1} \sin \left(\theta_{r}+2 / 3 \pi\right)+\lambda_{f 5} \sin \left(5 \theta_{r}+2 / 3 \pi\right) \\
& +\lambda_{f 7} \sin \left(7 \theta_{r}+2 / 3 \pi\right)+\lambda_{f 11} \sin \left(11 \theta_{r}+2 / 3 \pi\right) \\
& +\lambda_{f 13} \sin \left(13 \theta_{r}+2 / 3 \pi\right)+\ldots
\end{aligned}
$$

where, $\lambda_{f l}$ is fundamental magnitude of PM flux linkage and $\lambda_{f 5} \sim \lambda_{f 13}$ is harmonics magnitude of the interaction between the flux of the PM and the stator teeth. From (2), considering
BEMF harmonics, $\mathrm{d}$ and $\mathrm{q}$ axis flux linkages are represented by:

$$
\lambda_{d s}^{r}=\lambda_{f}+L_{d} i_{d s}^{r}, \lambda_{q s}^{r}=L_{q} i_{q s}^{r}
$$

where, $\lambda_{d f}$ and $\lambda_{q f}$ are $d$ and $q$ axis flux linkage. The harmonics of three phase PMSM can be represented by 6th and 12th harmonics. The $d$ and $q$ axis flux linkages are represented by:

$$
\begin{gathered}
\lambda_{d f}=\lambda_{f}+\lambda_{d f 6} \cos \left(6 \theta_{r}\right)+\lambda_{d f 12} \cos \left(12 \theta_{r}\right) \\
\lambda_{q f}=\lambda_{q f 6} \sin \left(6 \theta_{r}\right)+\lambda_{q f 12} \sin \left(12 \theta_{r}\right)
\end{gathered}
$$

where, the magnitude of 6th and 12th harmonics of $d$ and $q$ axis flux linkage is represented by:

$$
\begin{gathered}
\lambda_{d f 6}=5 \Psi_{f 5}+7 \Psi_{f 7} \\
\lambda_{d f 12}=11 \Psi_{f 11}+13 \Psi_{f 13} \\
\lambda_{q f 6}=5 \Psi_{f 5}-7 \Psi_{f 7} \\
\lambda_{d f 12}=11 \Psi_{f 11}-13 \Psi_{f 13}
\end{gathered}
$$

Finally, considering flux linkage harmonics, the electromagnetic torque of PMSM is represented by:

$$
T_{e}=\frac{3}{2} \frac{P}{2}\left(\lambda_{f} i_{q s}^{r}+\left(L_{d}-L_{q}\right) i_{d s}^{r} i_{q s}^{r}\right)+\frac{3}{2} \frac{P}{2}\left(\lambda_{d f} i_{q s}^{r}-\lambda_{q f} i_{d s}^{r}\right)
$$

Based on the $d$ and $q$ voltage equations and the BEMF data of experimental result, Fig. 6 (a) shows the proposed modeling of the PMSM using PSIM. Fig. 6 (b) shows the block diagram of the PMSM controller to determine the output characteristics of the PMSM.

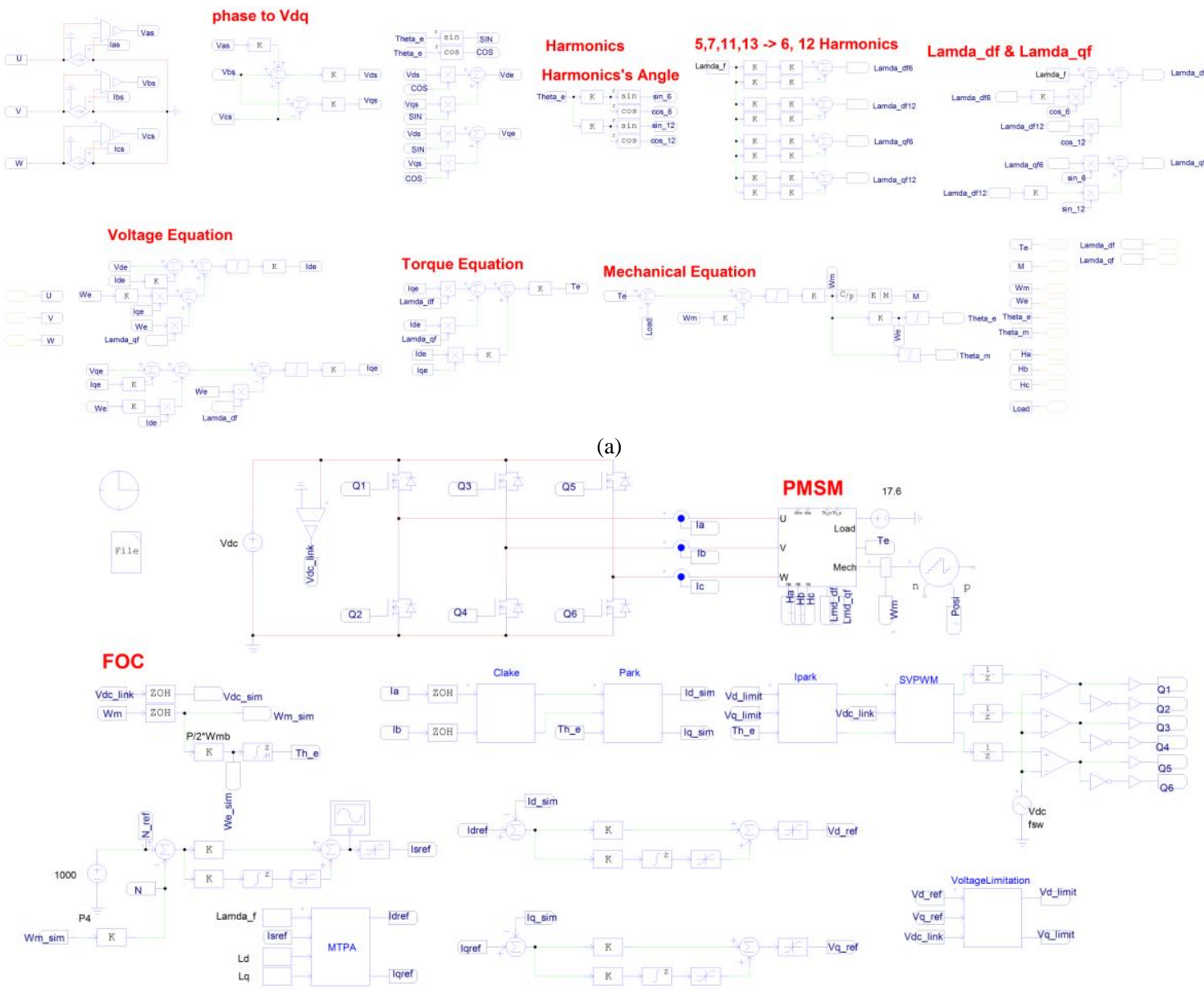

(b)

Fig. 6. Proposed modeling of PMSM using PSIM: (a) Block diagram of proposed modeling (b) Block diagram of PMSM controller. 


\section{COMPARISON OF OUTPUT CHARACTERISTICS}

Fig. 7 shows the comparison of the torque and phase current for the conventional modeling, experimental result and proposed modeling at $1000 \mathrm{rpm}$ and $17.6 \mathrm{Nm}$. For the conventional modeling, the phase current is the sinusoidal wave and output torque does not have a ripple. However, for the experimental result, the phase current and output torque have a ripple. In the case of the proposed modeling, the output characteristics are similar than the conventional modeling.

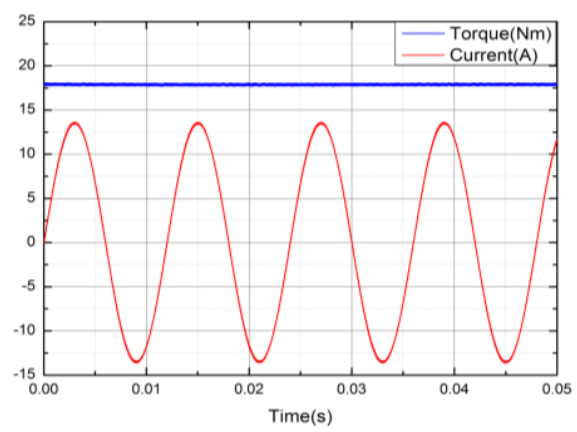

(a)

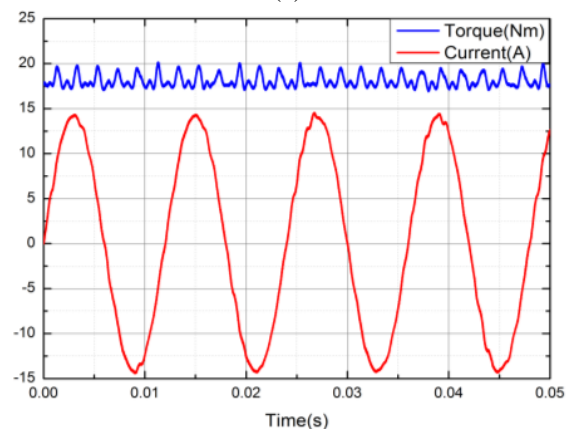

(b)

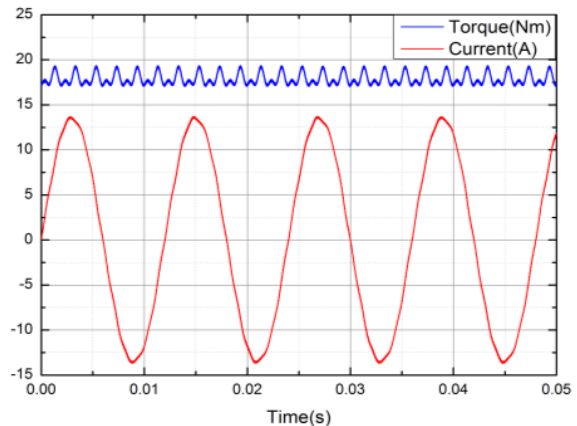

(c)

Fig. 7. Comparison of torque and phase current: (a) Conventional. (b) Experimental. (c) Proposed.

\section{CONCLUSION}

The general dynamic modeling is not able to determine the torque ripple characteristics because this modeling has only the magnetic and reluctance torque with the torque ripple component. Therefore, in this paper, the improved dynamic modeling of PMSM with torque ripple characteristics is proposed. The proposed modeling include the non-sinusoidal BEMF harmonics based on FEA and the experimental result. It is verified through the definition of equation, FEA and experimental result.

\section{REFERENCES}

[1] S. A. Kim, G. D. Choi, J. Lee, and Y. H. Cho, "Optimal rotor shape design of 3-step skew spoke type BLAC motor to reducing cogging torque," International Journal of Applied Electromagnetics and Mechanics, vol. 50, pp. S135-S145, 2016.

[2] J. H. Kim, K. Y. Cho, H. W. Kim, B. K. Lim, and B. M. Han, "Torque ripple reduction of PM synchronous motor for wide speed operating ranges," in Proc. ICPE-ECCE Asia, pp. 351-356, 2015.

[3] H.-K. Jeon, S.-A. Kim, M.-S. Lee, and Y.-H. Cho, "A study on the characteristics of IPMSM depending on permanent magnet," in Proc. KIEE Conf., 2014, pp. 713-714.

[4] S. Byun, S.-A. Kim, G.-J. Han, and Y.-H. Cho, "Study on Cogging Torque Reduction of Spoke type BLAC Motor," in Proc. KIEE Conf., pp. 241-243, 2016.

[5] Krishnan and Ramu, "Permanent magnet synchronous and brushless DC motor drives," CRC Press, 2009.

[6] A. M. El-Serafi and A. S. Abdallah, "Saturated synchronous reactances of synchronous machines," IEEE Trans. J. Ener., vol. 7, pp. 570-579, 1992.

[7] G. H. Kang, J. P. Hong, G. T. Kim, and J. W. Park, "Improved parameter modeling of interior permanent magnet synchronous motor based on finite element analysis," IEEE Trans. on Magn., vol. 36, pp 1867-1870, 2000.

[8] R. Krishnan, "Permanent magnet synchronous and brushless DC motor drives," CRC Press, 2010.

[9] W. Leonhard, "Control of electrical drives," Springer, 1966

[10] S. Li, C. Liao, S. Chen, and L. Wang, "Traction control of hybrid electric vehicle," in Proc. IEEE Vehicle Power and Propulsion Conf., 2009, pp. 1535-1540.
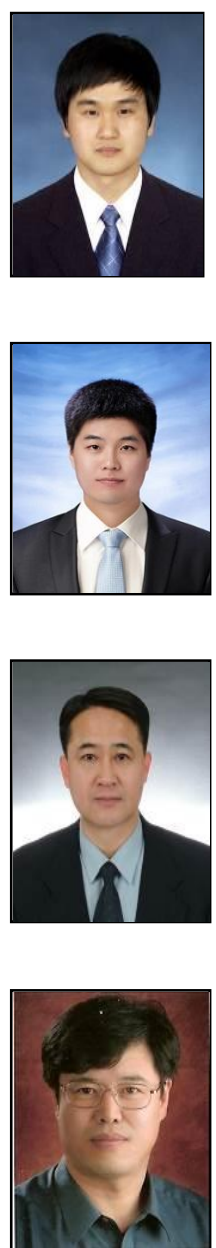

Sung An Kim received B.S and M.S degree in electrica engineering from Dong-A University in 2011 and 2013 respectively. In 2015, he joined Dong-A University, Power Electronics Applications Laboratory (PEAL), as a senior researcher. $\mathrm{He}$ is currently working toward the Ph.D. degree in electrical engineering with Dong-A University. His research interests are electrical machine and power electronics.

Ji Hyo Song received B.S degrees in electrical engineering from Dong-A university in 2015 . He is currently working toward the M.S degree in electrical engineering with Dong-A University. His research interests are electrical machine design.

ung Wo Han received B.S and M.S degrees in electrical engineering from Dong-A university in 1985 and 2015. In 1990, he joined Busan Transportation Corporation, R\&D center, as a researcher. $\mathrm{He}$ is currently working toward the Ph.D. degree in electrical engineering with Pukyong National University. His research interests are urban railway power substations and power electronics.

Yun Hyun Cho received B.S and M.S degree in electrical engineering from Han-Yang University in 1986 and 1991 respectively. From 1990 to 1995, he was a senior researcher at Korea Electro-technology Research Institute (KERI). In 1995, he joined Dong-A University, Department of Electrical Engineering, as a professor. His research interests are electrical machine and power electronics. 